\title{
Ensuring efficient operation of electromechanical systems with frequency regulation with periodic voltage sags
}

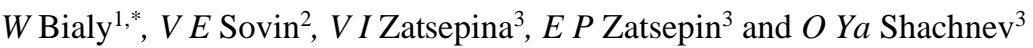 \\ ${ }^{1}$ Polytechnic University, Faculty of Organization and Management Institute of mechanical Engineering, Zabrze, 26 Roosevelt street, 41 - \\ 800 , Poland \\ ${ }^{2}$ Department of power supply, Kazan State Power Engineering University, Kazan, 51 Krasnoselskaya street, 420066, Russia \\ ${ }^{3}$ Department of electrical equipment, Lipetsk state technical University, Lipetsk, 30 Moskovskaya street, 398055, Russia
}

\begin{abstract}
The article reflects influence of high-power electricity consumers on control elements of frequency control of electric drive. Solution of problem of eliminating influence of voltage dips on electromechanical systems by means of a modern method of reactive power compensation is presented. Graphs of power, current, voltage versus time are presented, graphs of voltage curve are analyzed in detail with proposal of method of its normalization.
\end{abstract}

\section{Introduction}

Modern electrometallurgical enterprises in structure of power supply include both powerful power electrical equipment and auxiliary electric drive systems. Frequency control used to obtain maximum dynamic characteristics of electric motors. In addition to convenience in control of electric motors, using frequency-controlled drive can reduce production costs by reducing deterioration of equipment, extending its service life, increasing profitability of electric motors and continuous monitoring of its condition. Also, frequency control makes it possible to control speed of motor in accordance with nature of load. This, in turn, allows avoiding complex transient response in electrical networks, for ensuring operation equipment in most economical mode. This is relevant for both conveyor engines and engines of furnace-bucket unit, which is characterized by a long and re-short-term mode of operation, respectively [1-3].

Power part of electrometallurgical enterprises, which are arc steel furnaces, affects electrical equipment located electrically close. Their work is due to variable nature of load, because present non-constant and nonlinear values affect amount of power consumption, forming a wide range of operating amperage. As a result, negative factors affect other consumers on neighboring quiet tires [3-5]. Voltage fluctuations are directly related to fluctuation of amperage, if there is a sharp burst of amperage in arc furnace, respectively, there would be drop of voltage in network. This effect is very noticeable in melting period, where arc steel furnace operation mode is similar to shortcut circuit mode [6-8].

However, one of problems in field of frequencycontrolled drive is high sensitivity to disruption of quality of electrical energy, especially to voltage drops, which lead to activation protection of minimum voltage.
When it is triggered, control system blocks power keys of inverter, interrupting power of engine, as a result, engine enters run-out mode. Most negative consequences voltage drops causing in enterprises with a continuous technological cycle, when disruption of operating mode of one object entails disruption of entire production technology [9-11].

Taking into account above and based on findings [1], solution to problem of voltage dips on busbars of electric drive systems with frequency control is an effective compensation of reactive power on busbar of high-power electrical installations [11-13].

\section{Theoretical justification and conduct of experiment}

The main task to eliminate negative impact on power supply system is to maintain proper quality of electricity that meets modern requirements of this standard on "restless" system of busbars (system of busbars, which is connected to arc steel furnaces), because it is a kind of transit of negative effects on other elements of power supply system, including nearby consumers. We apply second type of STATCOM in this area of network (figure 1), namely - a multi-level transformerless. STATCOM provides regulation of output voltage and its phase. Voltage regulation on "restless" busbar is due to changes in reactive power consumed or issued to network

STATCOM system connected to "restless" $35 \mathrm{kV}$ busbar, which has alternating load (arc steel furnace DSP1), providing necessary quality of electricity [1415].

* Corresponding author: wbialy@ polsl.pl 


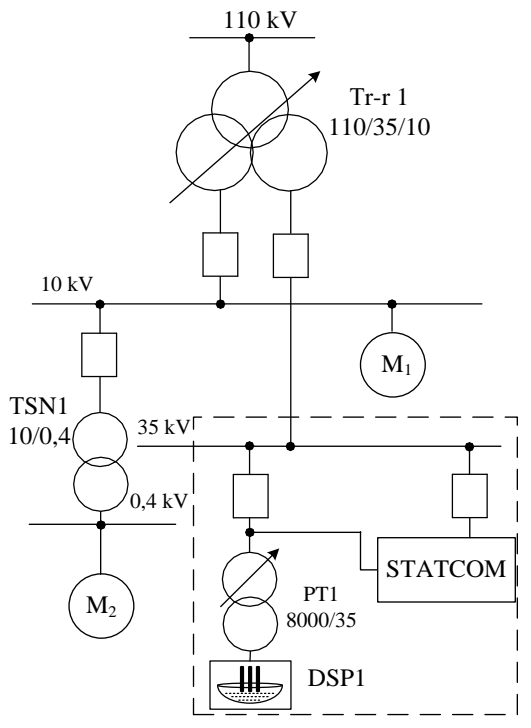

Fig. 1. Application of STATCOM.

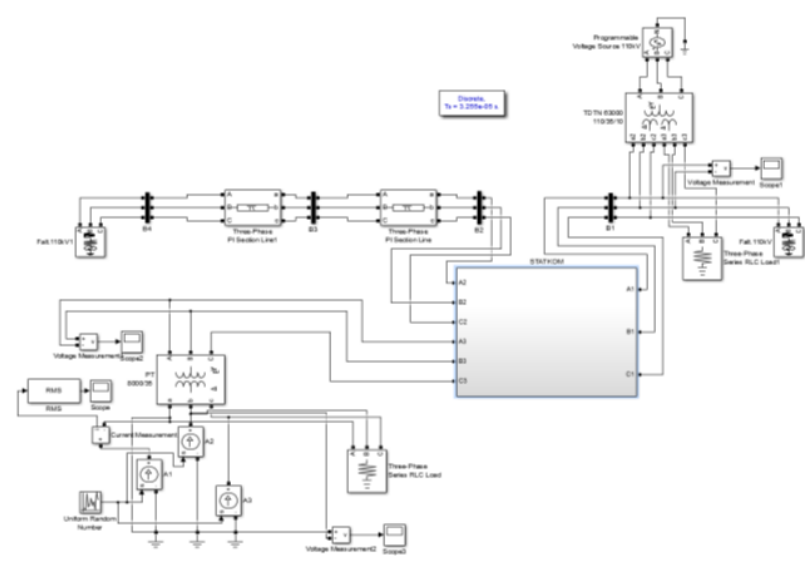

Fig. 2. Simulation model STATCOM in scheme.

As a result of modeling [1], diagram of power supply system shown in figure 1 in Simulink Matlab package is shown in figure 2. Graph of current load on electrode terminals of arc steel furnaces is shown in figure 3. Values of voltage on "restless" busbar are shown in figure 4 , figure 5 - shows values of amperage in each phase on supply to short network. It can be seen that after a time of $0.12 \mathrm{~s}$, it is already a permissible voltage on bus. In this scheme, controlled current sources performing sources of alternating load, where signal is formed by Uniform Random Number block, and with this in mind, model affects only metal melting process [16].

This period is most difficult for power supply system, during this period we can see highest frequency and amplitude of negative disturbances in network [17, 18]. Therefore, this period is most appropriate to consider with device of static reactive power compensators.

Principle of operation of STATCOM is identical to principle of operation of uninterruptible power supply units: from DC source voltage due to pulse width modulation and use of a harmonic filter, forming a sinusoidal voltage of $50 \mathrm{~Hz} \pm 3 \mathrm{~Hz}$. It is believed that today STATCOM is most perfect static FACTS. It has high speed, low content of higher harmonics, small size, can be used in any electrical networks. Use of STATCOM allows not only regulating voltage, but also to increase network capacity, optimize energy flux, improve shape of voltage curve, etc. Modification of STATCOM - active filter - allows you to compensate for almost all higher harmonics in networks.

Based on figure 4, STATCOM provides necessary quality of electricity with controlling power of line by generating or consuming a reactive component, and stabilizes voltages $\mathrm{U} 1$ and $\mathrm{U} 2$ at its ends. Consider voltage regulation method of controlling reactive energy flux. Voltage regulation due to impact on reactive energy flux on elements of electrical network is to when we change reactive power, we change voltage losses in reactive resistances change [3].

STATCOM system is a set of subsystems and is implemented by "Subsystems" blocks with inclusion of mathematical systems and electrical units. Let us consider how is working the key lock system STATCOM in event of an operational shortcut circuit in electrical installation. Three-level bridge circuits, which are protected against overload, are used as main converting elements. Add "Three-Phase Fault" block to a system to simulate a shortcut circuit on converter elements and set a signal to trigger this block. If we have a working block "Three-Phase Fault", the command to disable protected circuit will have given to "Three-Phase Breaker" element (figure 6). In our case, shortcut circuit time starts from time $t=1.2 \mathrm{~s}$, since load is modeled from previously developed model [1]. It is not difficult to notice that at time $\mathrm{t}=1.2 \mathrm{~s}$. there is a burst of

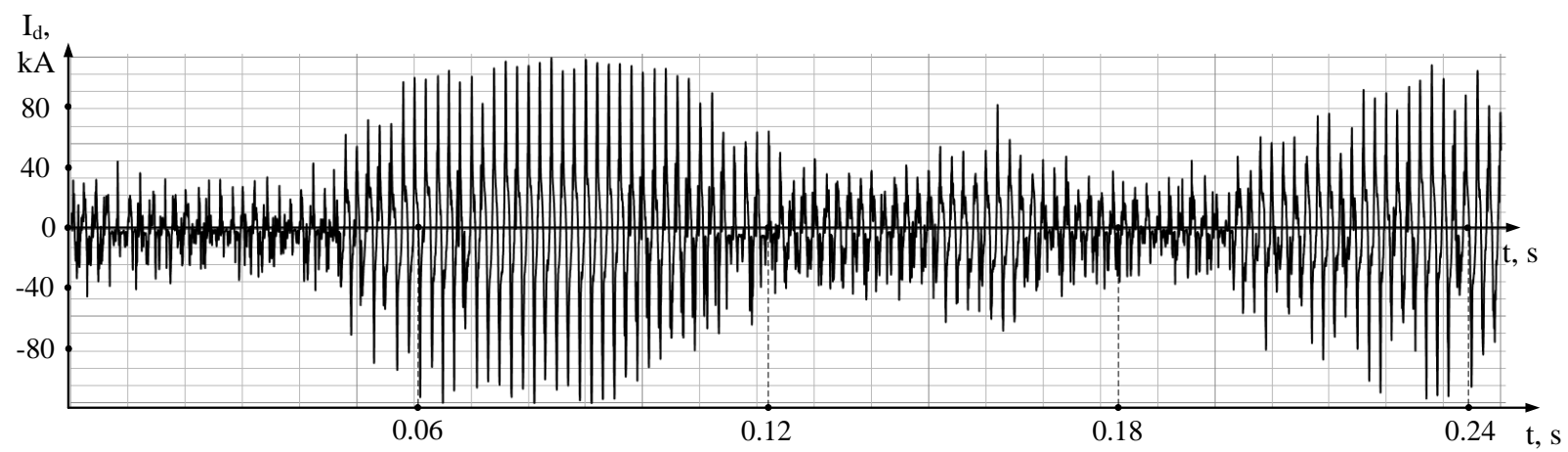

Fig. 3. Chart Ampacity arc furnace during melting. 


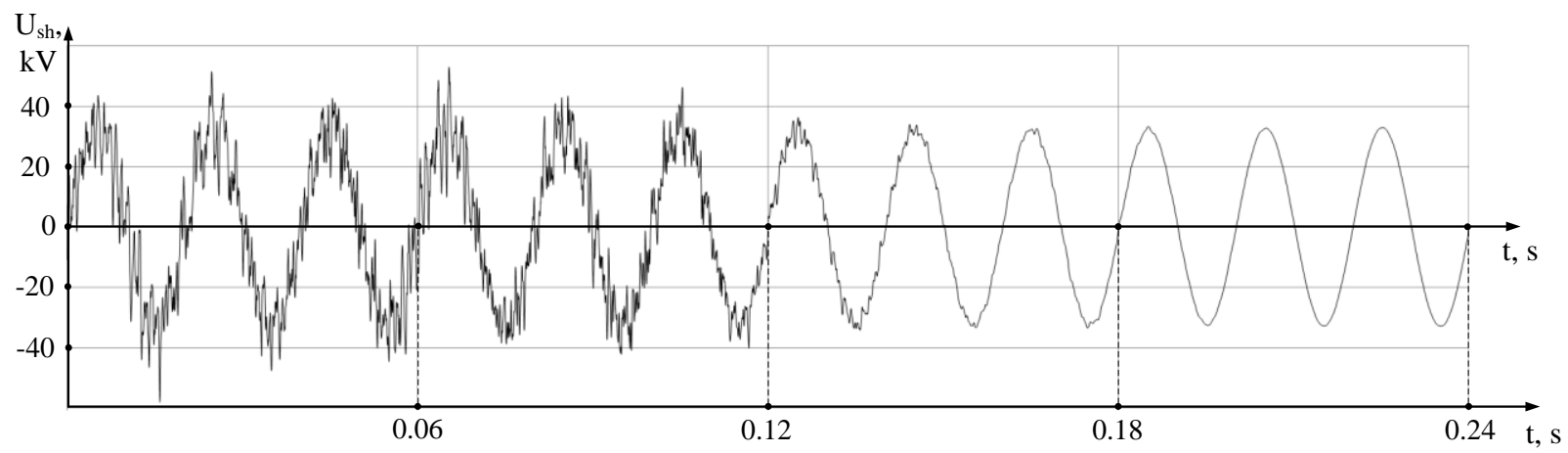

Fig. 4. Voltage values on "restless" bus $35 \mathrm{kV}$.

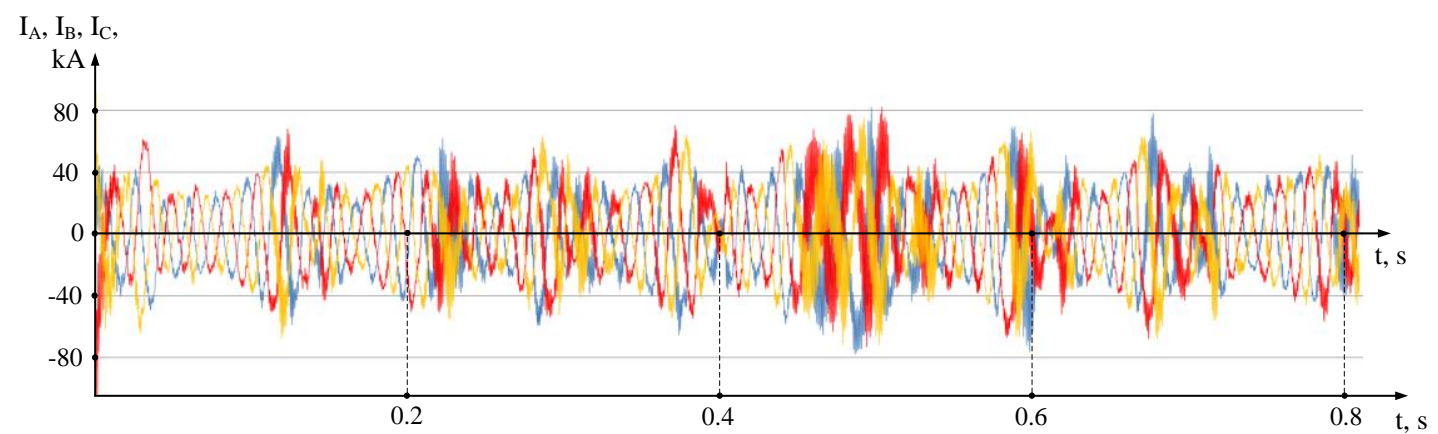

Fig. 5. Values of amperage in phase AVS to traverse short network.

amperage, accompanied by breakages of electric arcs. To indicate operation of converter elements, "Scope" unit is used, which displays voltage of bridge circuit at connection points in relative units [12]. Indication of presence of voltage is a graph formed by "Relay" block, i.e. in presence of voltage on converter element above zero value, block reflects value of function $U_{\mathrm{oe}}=1$, otherwise $-\mathrm{U}_{\mathrm{oe}}=0$.

Graph shows that voltage drops to zero values from time of 1.2 seconds, just at time when shortcut circuit begins and block goes into an inactive state due to closure of its "Three-Phase Breaker" key. After analyzing electrical condition of power supply system, control unit gives command to open. Thus, in view of this protective function, most hard mode of power supply system passes without compensation, taking into account recovery time.

According to this graph at time $\mathrm{t}=0.4 \mathrm{~s}$. busbar

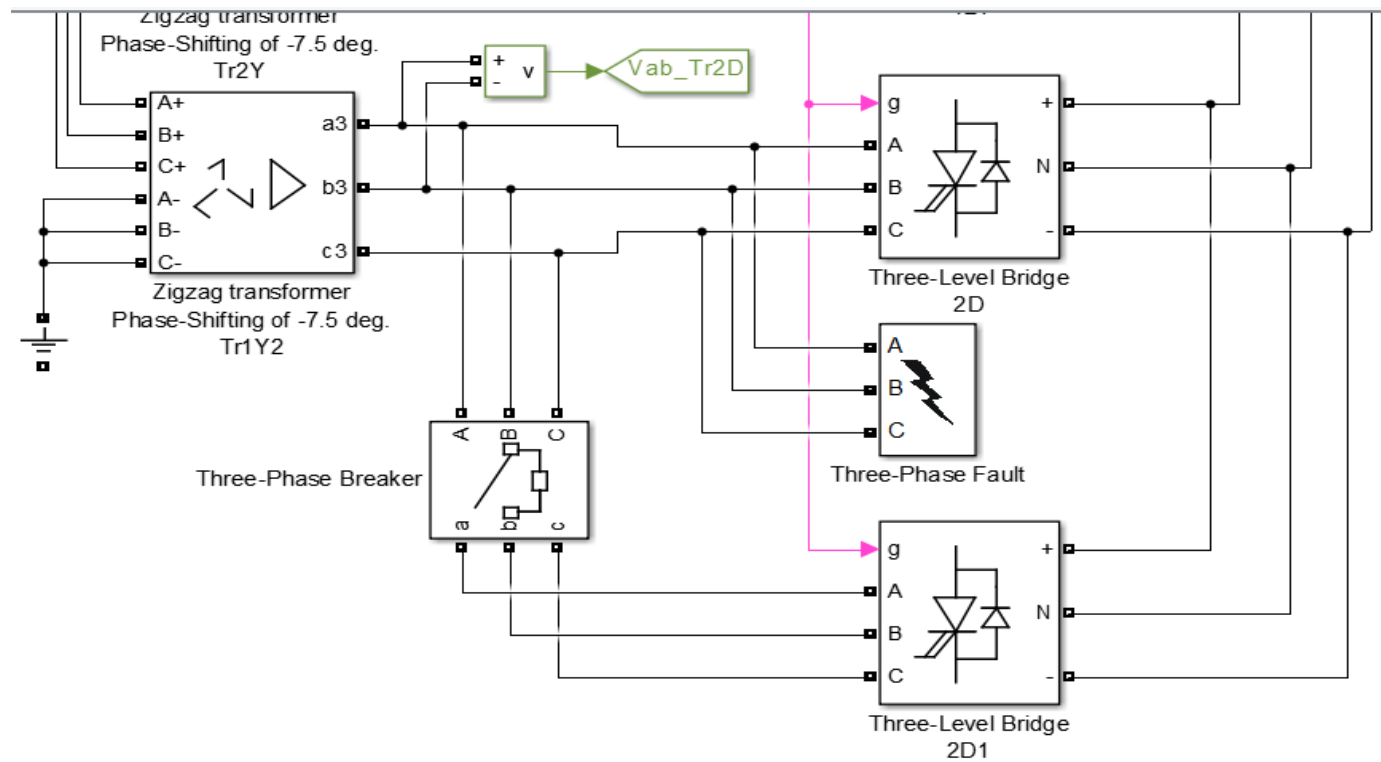

Fig. 6. Lock input key in system STATCOM. 


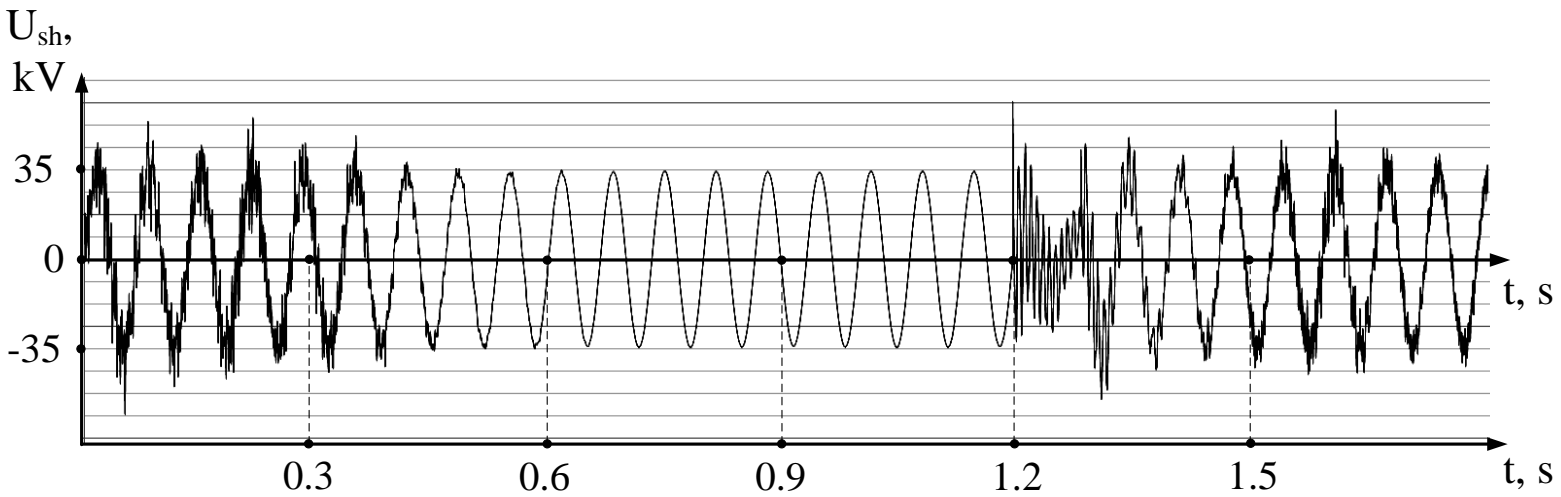

Fig. 7. Voltage on "restless" bus when keys are locked by STATCOM at time $\mathrm{t}=1.2 \mathrm{~s}$.

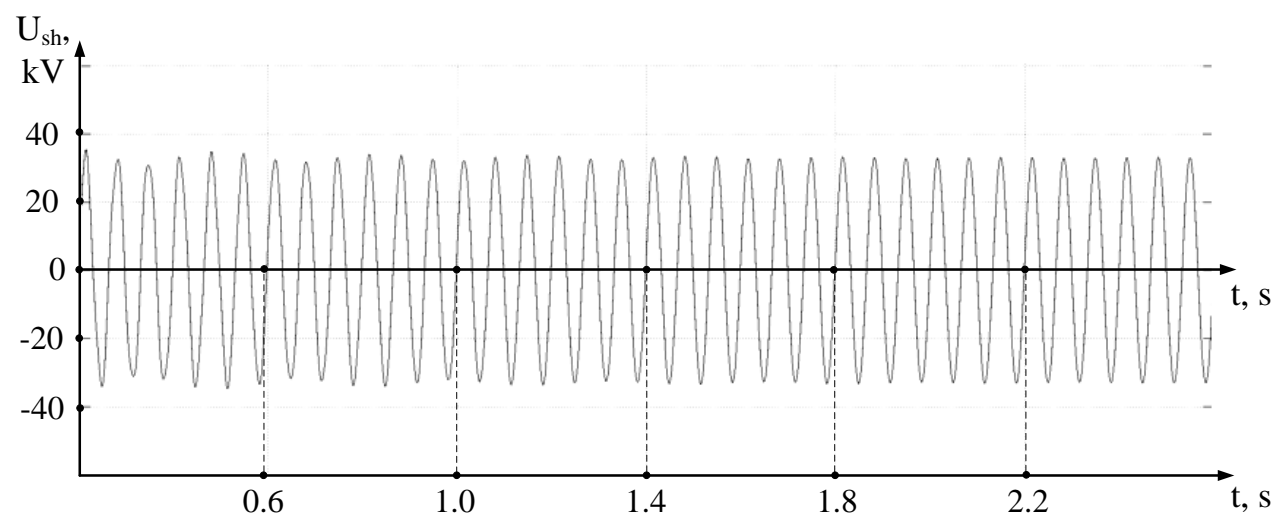

Fig. 8. Voltage on "restless" bus in absence of locking system keys STATCOM.

voltage has a value that meets standard requirements. But, at time $\mathrm{t}=1.2 \mathrm{~s}$. input keys of STATCOM are blocked, which affects voltage level, which exceeds three-fold value of normal voltage on busbar at a short time (due to transient response). Because there was a shutdown of converter blocks, accordingly, there are appears negative disturbing factors affecting performance of electrical installations and overall power supply system $[18,20]$.

\section{Conclusion}

In case of neutralizing blocking of converter blocks, voltage level will be within required range, and electrical complexes will have maximum efficiency, as well as performance of power supply system (figure 8).

According to above, ensuring neutralization of input keys of STATCOM system will have a positive impact on both electrical complexes and electric drive systems described at beginning of this article. This system will provide high rates of economic and technological efficiency of enterprise, which will have a positive impact on its competitiveness. Voltage fluctuations will be minimal, negative impact on frequency control of electric motors will not be carried out, which will have a positive impact on their technical and economic performance.

\section{References}

1. V.I. Zatsepina, E.P. Zatsepin, O.Ya. Shachnev, Ensuring effective functioning of compensating device STATCOM in metallurgical enterprises, Int. Russian Automation Conf, 1-6 (2018)

2. E.P. Zatsepin, Information-measuring system of EAF Steel, 3, 23-27 (2004)

3. O.V. Fedorov, Some features of structure internal systems power supply, Reliability and security of energy, 3, 30-33 (2015)

4. L. Shan, G. Herold, J. Jaeger, New approach to High speed for analysis of transient signals using, Wavelets Professional 7 Int. Conf. Change Of Government, 173176 (2001)

5. Z. Dianmin, D. Shijie, G. Xiaohong, E-Commercial$e$ is applied on market modem Power Syst. Machine, 11-14 (2001)

6. F.I. Senchukov, Reliability of electrical networks of power systems, 382 (1998)

7. A.N. Shpiganovich, V.I. Zatsepina, A.A. Shpiganovich, V.M. Stepanov, Power-supply systems reliability control, EAI Endorsed Transactions on Energy Web, 19, 155083 (2018)

8. E.P. Zatsepin, Information-measuring system for research of operation modes of receivers with varying nature of load, News of higher educational institutions in Chernozem region, 4, 6-12 (2012) 
9. A.N. Shpiganovich, A.A. Shpiganovich, V.I. Boichevskiy, Structural relationship of elements power supply systems, News of higher educational institutions in Chernozem region, 2, 3-12 (2017)

10. M.S. Ershov, A.V. Egorov, Y.V. Zarubica, Analysis of some methods for increasing stability of electrical systems with external disturbances, Industrial power engineering, 10, 25-29 (2003)

11. R.L. Fernández, G. Azzopardi, E. Alegre, N. Petkov, Machine-vision-based identification of broken inserts in edge profile milling heads, Robotics and ComputerIntegrated Manufacturing, 276-283 (2017)

12. A.N. Shpiganovich, A.A. Shpiganovich, O.V. Fedorov, Concerning the opportunity of fail-safe systems development, Int. Conf. on Industrial Engineering Application and Manufacturing (ICIEAM), 8076255 (2017)

13. A. Ya. Khrennikov, Monitoring informationmeasuring system for detecting power transformer faults, FRA and LVI-testing diagnostics experience, Reports of Asia-Pacific Power and Energy Engineering Conf., 102-106 (2012)

14. A.N. Shpiganovich, E. Yu. Voblikov, A.V. Rychkov, Evaluation effect of higher harmonic components on microprocessor devices in electrical systems, News of higher educational institutions in Chernozem region, 1, 12-21 (2018)

15. A.N. Shpiganovich, A.V. Boichevskiy, Choice of damping resistors on power for device limit switching overvoltage damping with three links, News of higher educational institutions in Chernozem region, 1, 3-11 (2018)

16. V.I. Zatsepina, E.P. Zatsepin, Reliability of power supply systems under influence of negative factors, Int. Conf. on Industrial Engineering Application and Manufacturing (ICIEAM), 1-4 (2017)

17. A.N. Shpiganovich, V.A. Korchagina, A.V. Rychkov, Blockchain in energy sector as latest technology of future, News of higher educational institutions in Chernozem region, 3, 36-40 (2018)

18. B.N. Parsunkin, O.V. Petrova, E.I. Polukhina, Research influence of electric mode DSP on cost produced steel, Theory and technology of metallurgical production, 44-46 (2014)

19. A.A. Filimonova, E.P. Zatsepin, V.I. Zatsepina, Multilevel control or power consumption at metallurgical plants, Int. Russian Automation Conf., 1-4 (2018)

20. A. Kiyoumarsi, M. Ataei, R. Hooshmand, Electric Arc Furnace Voltage Flicker Mitigation by Applying a Predictive Method with Closed Loop Control of TCR/FC Compensator, Journal of Electrical Engineering \& Technology, 1, 116-128 (2010) 